\title{
Injuries in child care centers: gender-environment interactions
}

Abbey Alkon, David R Ragland, Jeanne M Tschann, Janice L Genevro, Pamela Kaiser, W Thomas Boyce

\begin{abstract}
Objectives-To examine child characteristics (age, gender) and child care center environments (socioemotional quality, physical safety) that jointly predict injuries for preschool children.

Methods-A two year prospective study of 360 preschool children, ages 2-6 years, was conducted in four urban child care centers. Composite scores for center quality and physical safety were derived from on-site observations, and injury rates were based on teacher reports. Poisson regression analyses examined age, gender, center quality, center safety, and the interactions of gender with quality and safety as predictors of injury incidence over one child year.
\end{abstract}

Results-Age was significantly associated with injury rates, with younger children sustaining higher rates. An interaction between gender and center quality also significantly predicted injury incidence: girls in low quality centers experienced more injuries, while girls in high quality centers sustained fewer injuries than their male peers. Finally, an interaction between gender and center safety showed that girls in high safety centers sustained more injuries than boys, while girls in low safety centers sustained fewer injuries.

Conclusions-Injuries occur even in relatively safe environments, suggesting that in child care settings, the socioemotional context may contribute, along with physical safety, to the incidence of injury events. Further, gender specific differences in susceptibility to environmental influences may also affect children's vulnerability and risks of injuries. The prevention of injuries among preschool children may thus require attention to and modifications of both the physical and socioemotional environments of child care.

(Injury Prevention 2000;6:214-218)

Keywords: gender; environment; child care centers

Menlo Park, California

P J Kaiser

University of California, Berkeley

School of Public

Health, Division of

Health and Medical

Sciences, Berkeley,

California

W T Boyce

Correspondence to:

Dr Alkon (email: abbeyalk@

uclink4.berkeley.edu)

Injury studies conducted in child care cent generally identify either demographic or environmental factors associated with injury rates, ${ }^{1-5}$ but seldom examine the combined effects of both. Younger preschool children, for example, are known to have more injuries than older preschool children, ${ }^{15}$ and boys often have more severe injuries than girls. ${ }^{135}$ Further, it has been established that the physical environ- ment and structural characteristics of outdoor play equipment, such as type, height, and impact surfaces, can also affect child injury rates. ${ }^{367}$ It is not yet known, however, whether age or gender interacts with such structural characteristics in the prediction of injury incidence or severity.

Although attention to the physical environment is clearly important, other aspects of the environment may also affect injury risk. For example, the socioemotional quality of a child care center's environment-for example, aspects of curriculum, teacher-child interactions, staff stability, group size, adult-to-child ratios, and teacher education ${ }^{8-11}$ is also plausibly related to injury rates in young children. ${ }^{12} 13$ Children's relationships to their environments are also transactional in nature, and while an environment may have differential impacts on individual children (for example, children of different genders and temperaments), ${ }^{14}$ children's behavior may also change their environments. Thus, behavioral characteristics, such as activity level ${ }^{15-17}$ and aggression, ${ }^{18}{ }^{19}$ may alter play activities and peer relationships, thereby affecting the risk of injury in a child care setting.

Although severe childhood injuries are a major public health concern, children in child care centers rarely sustain severe injuries. These account for only $1 \%$ of those reported in US centers. ${ }^{12}$ Children who sustain frequent minor injuries, however, are more likely to sustain subsequent severe injuries. ${ }^{20}$ Thus, studies of frequent minor injuries may identify important risk factors for the prevention of more severe injury events. ${ }^{21}$ The research question addressed by this study was: Do child demographic characteristics (age, gender) and child care center environments (socioemotional quality, physical safety) jointly predict child injury rates (minor and severe) for preschool age children attending urban child care centers?

\section{Methods}

The reported data were collected as one component of a larger research project investigating the relation between environmental stressors and health in preschool age children attending child care centers. $^{22}$
SUBJECTS

A total of 360 children enrolled in four urban child care centers were studied during a two year period from January 1990 through December 1991. Information on date of birth, gender, date of study enrollment, and center 
Table 1 Center characteristics: gender, outdoor equipment, quality and safety dimension and composite scores

\begin{tabular}{|c|c|c|c|c|}
\hline & \multicolumn{4}{|l|}{ Center } \\
\hline & $A$ & $B$ & $C$ & $D$ \\
\hline \multicolumn{5}{|l|}{ Gender } \\
\hline No $(\%)$ males & $76(49)$ & $35(58)$ & $61(54)$ & $25(76)$ \\
\hline No (\%) females & $78(51)$ & $25(42)$ & $52(46)$ & $8(24)$ \\
\hline Equipment outside & $\begin{array}{l}\text { Climbing structure, } \\
\text { bars, trikes, benches }\end{array}$ & $\begin{array}{l}\text { Swings, slide, pole, } \\
\text { play house, art table, } \\
\text { trikes }\end{array}$ & $\begin{array}{l}\text { Tire swing, structure, } \\
\text { pole, crates, trikes }\end{array}$ & $\begin{array}{l}\text { Metal dome, wood } \\
\text { house }\end{array}$ \\
\hline \multicolumn{5}{|l|}{ Quality dimensions: } \\
\hline ECERS total score & 241 & 251 & 180 & 209 \\
\hline Staff stability (turnover \%) & 34 & 58 & 27 & 133 \\
\hline Full time/all staff ratio & $8 / 9$ & $1 / 12$ & $5 / 13$ & $0 / 6$ \\
\hline Quality composite score ${ }^{\star}$ & 0.71 & -0.04 & -0.37 & -1.81 \\
\hline \multicolumn{5}{|l|}{ Safety dimensions: } \\
\hline Equipment height (inches) & 66 & 54 & 78 & 50 \\
\hline Child density $\left(\mathrm{ft}^{2} /\right.$ child $)$ & 70 & 260 & 64 & 115 \\
\hline Outside adult/child ratio & $1 / 8$ & $1 / 6$ & $1 / 11$ & $1 / 5$ \\
\hline Safety composite score $†$ & -0.20 & 1.40 & -0.92 & 1.43 \\
\hline
\end{tabular}

†Cronbach's $\alpha$ coefficient $=0.88$.

leave date were obtained from center records. This study was approved by the Committee for Human Research of the University of California, San Francisco and the Committee for Protection of Human Subjects of the University of California, Berkeley.

Ages at study entry ranged from 2-6 years (mean $=3.7$ years), and $55 \%(n=197)$ were boys. While girls were more evenly distributed by age, there were more boys in the 3.5-6 year age group $(61 \%)$ than there were in the $2-3.5$ year age group (49\%). The mean time children were enrolled in the study was 46 weeks or 1840 child care hours.

INJURY DEFINITION AND DATA COLLECTION Data were collected on standardized reporting forms completed by teachers when an injury met the study definition, as "an event resulting in bodily harm, reflected by a physical mark or a sustained complaint more than five minutes in duration". ${ }^{23}$ The definition was based on objective, observable indicators in order to reduce subjective reporting. Injuries were designated as minor (superficial cuts, bumps, bruises, and bites), moderate (deep cuts, crush injuries, multiple cuts, burns, chipped teeth, or fractures), or severe (those requiring medical attention and/or telephone contact with parents).

Injury rates were calculated as: (total number of injuries/total exposure time in hours) $\times 2000$ exposure hours. The denominator (base value) of 2000 hours was equivalent to a full time child's presence in a child care center for 50 weeks, eight hours/day. Total exposure time was the number of hours enrolled in the center during the study period, calculated as: ( $n$ weeks enrolled $) \times(n$ days/week $)) \times($ hours/day).

CHILD CARE CENTERS

Two centers were university affiliated, and two were private, but non-profit. Children were in the centers an average of eight hours/day, and centers were open an average of 50 weeks/year. Each center was licensed and in compliance with California state regulations.

Injury data were collected over two study years on all study children in three of the four centers. In the remaining center, only first year's data were analyzed because of inconsistent data collection in the second. Data were also collected on: (a) the quality of the center's socioemotional environment and (b) physical safety measures.

The quality of the child care environment included three dimensions: the global socioemotional environment, staff stability, and proportion of full time staff (table 1). The global environment was evaluated with the early childhood environmental rating scale (ECERS), an observational measure with 37 items comprising seven subscales: language and reasoning activities, social development, creative activities, personal care, fine/gross motor activities, furnishings/display, and adult facilities/opportunities. ${ }^{11}$ The total ECERS score was used because it had the strongest internal consistency (Cronbach's $\alpha=0.83$ ) and the subscales were highly intercorrelated. ${ }^{94}$ Annual observations were conducted in each classroom of all four centers by a trained researcher who had achieved $90 \%$ inter-rater reliability with an expert. Classroom ratings were averaged to create quality scores for each center. Staff stability was calculated as ((number of staff who left in one year/average number of staff/year) $\left.{ }^{\star} 100\right)$. The full time/all staff ratio reflected the number of staff a child related to during an eight hour day, and was calculated as the number of full time staff divided by total number of full and part time staff.

Because the three environmental quality dimensions were highly correlated, a composite score was created by standardizing and summing the three dimensions for each center annually. Each child was assigned a quality composite score based on the center attended. The physical safety of the playgrounds also included three dimensions: equipment height, ratio of adults to children, and child density ratio (table 1). ${ }^{1561225}$ As with the score for environmental quality, a safety composite score was derived by standardizing and summing the three component measures.

DATA ANALYSES

Mean and median injury rates were calculated by gender and age category (2.0-3.5 and 3.6- 


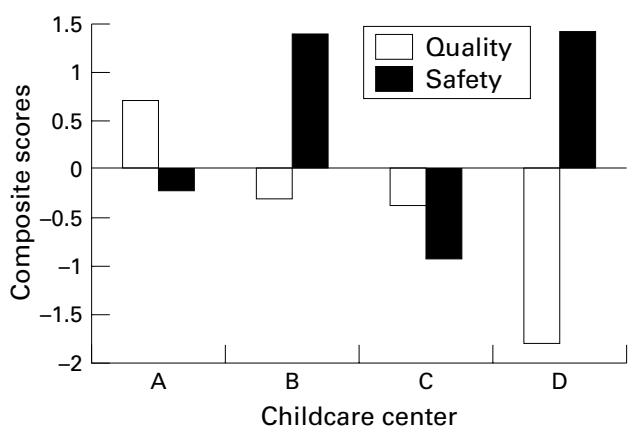

Figure 1 Center by quality and safety composite scores.

Table 2 Gender and age by mean (confidence interval, CI) and median injury rate/2000 exposure hours (equivalent to one child year)

\begin{tabular}{|c|c|c|c|c|}
\hline Variable & No (\%) & $\begin{array}{l}\text { Mean injury } \\
\text { rate }(95 \% \text { CI) }\end{array}$ & Median & Range \\
\hline \multicolumn{5}{|l|}{ Gender^ } \\
\hline Boys & $197(55)$ & $6.4(6.0$ to 6.8$)$ & 4.5 & $0-38$ \\
\hline Girls & $163(45)$ & $5.0(4.6$ to 5.3$)$ & 3.0 & $0-47$ \\
\hline \multicolumn{5}{|c|}{ Age in years $\dagger$} \\
\hline $2.0-3.5$ & $174(48)$ & 6.8 (6.5 to 7.3$)$ & 5.1 & $0-47$ \\
\hline $3.6-6.0$ & $186(52)$ & $4.5(4.2$ to 4.9$)$ & 2.9 & $0-38$ \\
\hline Total & $360(100)$ & $5.7(5.4$ to 6.0$)$ & 3.8 & $0-47$ \\
\hline
\end{tabular}

${ }^{\star} t$ Statistic $(\mathrm{df})=1.93(358), \mathrm{p}=0.05$ (mean).

$\mathrm{Z}$ statistic $=-2.53, p=0.01$ (median).

$\dagger t$ Statistic $(\mathrm{df})=2.47$ (334), $\mathrm{p}=0.01$ (mean)

$\mathrm{Z}$ statistic $=2.72, p=0.01$ (median) .

6.0 years) with $95 \%$ Poisson confidence intervals. To compare mean injury rates $t$ tests were used, and rank sum tests compared median injury rates by gender and age.

Poisson regression was used to model predictive associations between age, gender, the quality and safety of centers, and injury rates. Cross product terms were created to represent the interactions of gender with quality and safety, and age with gender, quality, and safety. The Poisson regression model was calculated as: $\log$ (\# injuries) $=\mathrm{a}+\mathrm{b} 1$ (age) + b2 (gender) + b3 (safety composite) + b5 (gender ${ }^{\star}$ quality) $+\mathrm{b} 6$ (gender ${ }^{\star}$ safety) + log (exposure hours). The dependent variable, child injury rate, included both minor and moderate-to-severe injuries. The coefficients of the independent variables were interpreted as rate ratios. The advantage of Poisson regression over a linear regression model in this research application is that the Poisson model analyzes rates, controls for exposure time, and does not require continuous, Gaussian data. ${ }^{26}{ }^{27} \mathrm{An}$ additional Poisson regression model used moderate-severe injury rates as the dependent variable, as a comparison with the total injuries model. Statistical significance for analyses was set at an $\alpha$ level of $\mathrm{p}<0.05$, and data were analyzed using Stata Statistical Software.

Table 3 Results of Poisson regression model predicting the injury rate ratio $(R R)$ $(n=360)^{*}$

\begin{tabular}{llllll}
\hline Variable & Coefficient & $Z$ statistic & $p$ Value & $R R$ & $95 \%$ CI (RR) \\
\hline Age (years) & -0.34 & -11.00 & $<0.01$ & 0.71 & 0.67 to 0.75 \\
Gendert & -0.24 & -4.90 & $<0.01$ & 0.79 & 0.72 to 0.87 \\
Quality & 0.03 & 0.28 & 0.78 & 1.03 & 0.85 to 1.24 \\
Safety & 0.13 & 1.61 & 0.11 & 1.14 & 0.97 to 1.33 \\
Gender and quality & -0.20 & -3.11 & 0.01 & - & - \\
Gender and safety & 0.19 & 3.62 & $<0.01$ & - & - \\
\hline
\end{tabular}

${ }^{\star}$ Log likelihood $=-1180.221$.

†Gender: $1=$ male; $2=$ female. $\mathrm{CI}=$ confidence interval.

\section{Results}

Altogether 1886 injuries were reported over the two year study period, with a mean (median) child injury rate of 5.7 (3.8) per 2000 exposure hours. The distribution was skewed, with a range of 0-47 injuries per 2000 hours. Ninety per cent of injuries were minor, while $10 \%$ were moderate-severe; $74 \%$ occurred on the playground.

Table 1 summarizes the gender distributions, outdoor equipment, quality and safety dimension measures, and composite scores for the four child care centers. Figure 1 shows that the distributions of quality and safety composite scores by center reveal no notable covariance in composite scores within centers. Higher scores reflect higher quality and better safety, and in this study there were no centers with both high quality and high safety.

Median injury rates differed significantly by gender $(Z$ statistic $=-2.53, p=0.01)$ and age category $(Z$ statistic $=2.72, p=0.01)($ table 2$)$. Boys had significantly higher rates of injury than girls, and younger children were at significantly greater risk than their older peers. However, there was also a significant gender difference in the mean time enrolled in the study (girls' mean $=12$ months, boys' mean $=9.6$ months $)(t(\mathrm{df})=2.49(342), \mathrm{p}=0.01)$.

Poisson regression analyses indicated that age, gender, and interactions between gender and center environment (both safety and quality) significantly predicted rates of injury (table 3). For each one year increase in age, there was a $29 \%$ decrease in injury rate (rate ratio 0.71 , confidence interval 0.67 to 0.75 ).

Gender was a statistically significant predictor of injury rates as a main effect $(p<0.01)$ and in interaction with center quality $(\mathrm{p}=0.01)$ and safety $(p<0.01)$. Although center quality and safety showed significant main effects with no interaction terms in the model, these effects were subsumed in the interaction terms in the larger regression model. Importantly, with all main and interaction terms included, the effects of center quality and safety on injury rates were modified by the influence of gender. Specifically, both girls and boys had higher rates in centers characterized by low quality and high safety, but the effects were more apparent in girls than in boys. The injury rate among girls in low quality centers was 7 per 2000 exposure hours, compared with a rate of 4 per 2000 among girls in high quality centers (fig 2). In contrast, boys had similar rates regardless of center quality.

Paradoxically, and unexpectedly, girls had the highest expected injury rates in high safety centers ( 8 per 2000 exposure hours) and the lowest rates in low safety centers (4 per 2000 exposure hours) (fig 3 ). Boys had similar rates regardless of center quality.

Supplementary analyses with moderatesevere injuries as the dependent variable revealed the same set of predictor variables (age, gender, quality, and quality ${ }^{\star}$ gender), except for the safety composite score. 


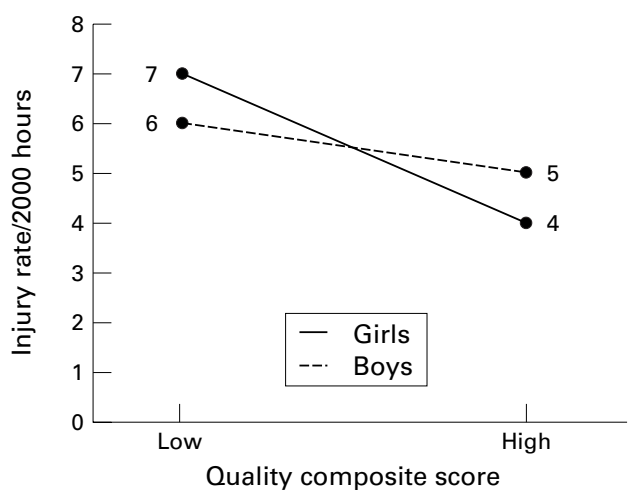

Figure 2 Expected injury rate 2000 exposure hours by gender and child care quality $(n=360)$. Expected rates are calculated based on the Poisson regression model.

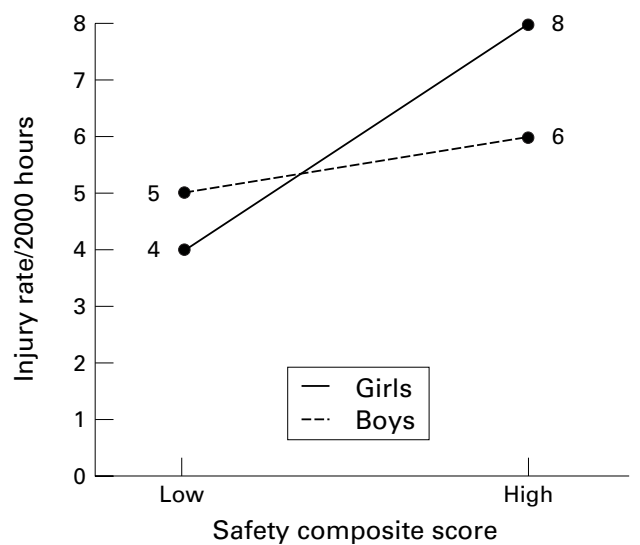

Figure 3 Expected injury rate/2000 exposure hours by gender and child care safety $(n=360)$. Expected rates are calculated based on the Poisson regression model.

\section{Discussion}

This study's two principal findings offer new insights into the independent and combined effects of child characteristics and child care center environments on preschool injury rates. First, and predictably, younger preschool children sustained more injuries than older children, and rates for boys were higher than for girls. These findings are commensurate with other reports of injury rates in preschool children. ${ }^{15}$

Second, girls' rates varied more than those of boys' with variation in both physical and socioemotional environments of child care. Thus, higher injury rates were found for both sexes in low quality and high safety contexts, but these effects were of significantly greater magnitude for girls than boys. Girls had either the highest or lowest injury rates, depending on the character of the child care environments in which they were placed. This finding is unlikely to be due to a confounding of environmental effects, because quality and safety did not co-vary in any of the centers, indicating true independence of these environmental factors.

There are plausible, though admittedly post hoc, explanations for the unexpected findings that high safety centers had higher rates of injuries and that the injury augmenting effects of low quality, high safety settings were greater in girls. The higher safety scores of centers with higher injury rates could be a consequence, rather than an antecedent of injury events because centers with higher injury rates could have responded with more stringent safety standards. Supporting this explanation was the finding that the physical safety of the environment was a significant factor when predicting all injuries, but not moderate-severe injuries alone.

Further, the greater environmental effects in girls could be attributable to greater sensitivity or susceptibility among preschool age girls to the quality of the socioemotional environment that influences injury occurrences. In this study, girls in higher quality centers may have formed more positive attachment relationships with a stable and full time staff,, 10 thereby enhancing socially competent behaviors ${ }^{28-30}$ and lowering injury rates. Girls in low quality centers may have been less able to resolve peer conflicts skillfully in the absence of secure attachment relationships and may therefore have been at greater risk of injuries.

Lastly, girls in high safety centers may have been more aware of the safe environment and may therefore have engaged in more frequent risk taking behavior. Perceptions of safety, particularly in young children, may paradoxically release, rather than discourage, risk taking behavior. Further, gender specific play behaviors may be changing for preschool children attending full day child care, and the stereotypic view that boys engage in more risk taking behavior than girls may be increasingly inaccurate. $^{31}$

\section{LIMITATONS}

Our study had several limitations that constrain its generalizability beyond similar populations attending mid to high quality child care centers. Although the sample was moderately large, the number of centers was small $(n=4)$. Further, while the safety composite score included important information on center characteristics that may affect safety, the score omits other predictive factors, such as time spent on playground equipment, ${ }^{32} 33$ the number and types of equipment, ${ }^{34-36}$ and the condition and age of equipment. ${ }^{37}$ Finally, both quality and safety composite scores included observable, objective indicators of environmental attributes, but did not address children's behavior. Therefore, the study overlooked contextual risks created by the presence of other children.

Future child care injury research should attend to both physical and socioemotional environmental factors, as well as family and child behavioral characteristics, in order to elucidate the combined effects of child and context on early childhood injury rates.

\section{Implications for prevention}

These findings support injury prevention efforts designed to improve physical and socioemotional environmental standards for child care, and that foster parent education about quality indicators in child care. Every state in the US should regulate child care standards to ensure low child density ratios, and appropriate equipment condition and 
height, ${ }^{38}$ because these factors, and others, affect the physical safety of the environment.

Preschool injuries are influenced, however, not only by the physical safety of the environment, but by the socioemotional quality of the child care centers, as well. Child care quality, in this study, exerted significant, independent, and measurable effects on injury rates. The socioemotional environment is affected by child care staffing standards, such as adult/child ratios, staff stability, and staff educational level. Low adult/child ratios affect the supervising staff's ability to prevent injuries by intervening before they occur, teaching conflict resolution skills, and encouraging cooperative, nonviolent play.

Prevention efforts can also focus on staff stability and education. Centers that pay staff higher, above standard wages have lower staff turnover, ${ }^{39}$ and a stable staff provides closer, trusting teacher-child relationships. Higher education standards for child care teachers (for example, teachers with college degrees), would improve the quality of teacher-child interactions, support a developmentally appropriate curriculum, and likely encourage more gender neutral play. ${ }^{40}$ Children attending high quality centers with highly trained staff have better developmental, cognitive, and health outcomes than children in low quality centers. ${ }^{10} 4142$

Parents with young children need more information about known quality indicators when choosing child care for their children. It would be helpful, for example, if parents were informed about the risk factors identified in this and other studies affecting child care injury rates. Multifaceted injury prevention efforts, with an emphasis on high standards for both physical safety and socioemotional environmental quality, may yield even greater reductions in avoidable injuries to preschool children.

The authors gratefully acknowledge the families and child care staff for their time and support of the study. Funding for this staff for their time and support of the study. Funding for this
study was provided by NICHD (1R01 HD24718) and the first study was provided by NICHD (1R01 HD24718) and the first author received additional support from the
of Health Training Grant (T32-HL07365).

1 Chang A, Lugg MM, Nebedum A. Injuries among preschool children enrolled in day-care centers. Pediatrics preschool child

2 Lee E, Bass C. Survey of accidents in a university day-care center. F Pediatr Health Care 1990;4:18-23.

3 Sacks J, Smith JD, Kaplan KM, et al. The epidemiology of injuries in Atlanta day-care centers. $\mathcal{F} A M A$ 1989;262: 1641-5.

4 Leland N, Garrard J, Smith DK. Injuries to preschool-age children in day-care centers: a retrospective record review. Am F Dis Child 1993;147:826-31.

5 Elardo R, Solomons HC, Snider BC. An analysis of accidents at a day care center. Am f Orthopsychiatry 1987; 57:60-5.

6 Runyan C, Gray DE, Kotch JB, et al. Analysis of US child care safety regulations. Am f Public Health 1991;8:981-5.

7 Bond M, Peck MG. The risk of childhood injury on Boston's playground equipment and surfaces. Am f Public Health 1993;83:731-5.

8 Howes C, Phillips DA, Whitebrook M. Thresholds of quality: implications for the social development of children quality: implications for the social development of child

9 Phillips DA, McCartney K, Scarr S. Child-care quality and children's social development. Dev Psychol 1987;23:53743.

10 Phillips DA, ed. Quality in child care: what does research tell us? 3rd Ed. Washington, DC: National Association for the Education of Young Children, 1993: 129.
11 Harms T, Clifford RM. Early childhood environment rating scale. New York: Teachers College, 1980: 40.

12 Coppens N, Gentry LK. Video analysis of playground injury-risk situations. Research in Nursing $\mathcal{G}$ Health 991; 14:129-36.

13 Sacks J, Brantley MD, Holmgreen P, et al. Evaluation of an intervention to reduce playground hazards in Atlanta child-care centers. Am F Public Health 1992;82:429-31.

14 Schwebel D, Plumert J. Longitudinal and concurrent relations among temperament, ability estimation, and injury proneness. Child Dev 1999;70:700-12.

15 Horwitz S, Morgenstern H, DiPietro L, et al. Determinants of pediatric injuries. Am F Dis Child 1988;142:605-11.

16 Bijur P, Golding J, Haslum M. Persistence of occurrence of injury: can injuries of preschool children predict injuries of school-age children? Pediatrics 1988b;82:707-12.

17 Matheny A, Brown AM, Wilson RS. Behavioral antecedents of accidental injuries in early childhood: a study of twins. $\mathcal{F}$ Pediatr 1971;79:122-4.

18 Manheimer D, Mellinger GD. Personality characteristics of the child accident repeater. Child Dev 1967;38:491-513.

19 Bijur P, Stewart-Brown S, Butler N. Child behavior and accidental injury in 11,966 preschool children. Am f Dis Child 1986;140:487-92.

20 Alkon A, Genevro JL, Kaiser PJ, et al. Injuries in child-care centers: rates, severity, and etiology. Pediatrics 1994;94: 1043-6.

21 Kotch JB, Dufort VM, Stewart P, et al. Injuries among children in home and out-of-home care. Inj Prev 1997;3:26771.

22 Boyce W, Chesney M, Alkon A, et al. Psychobiologic reactivity to stress and childhood respiratory illnesses: results of two prospective studies. Psychosom Med 1995;57: 411-22.

23 Alkon A, Genevro J, Kaiser P, et al. The epidemiology of injuries in 4 child care centers. Arch Pediatr Adolesc Med 1999;153:1248-54.

24 McCartney K. Effect of quality of day care environment on hildren's language development. Dev Psychol 1984;20: $244-60$

25 Sacks JJ, Holt KW, Holmgreen P, et al. Playground hazards in Atlanta child care centers. Am $\mathscr{f}$ Public Health 1990;80:986-8.

26 Selvin S. Practical biostatistical methods. San Francisco: Duxbury Press, 1995.

27 Frome E, Checkoway H. Use of poisson regression models in estimating incidence rates and ratios. Am f Epidemiol 1985;121:309-23.

28 Howes C, Stewart P. Child's play with adults, toys, and peers: an examination of family and child-care influences. Dev Psychol 1987;23:423-30.

29 Vandell D, Henderson VK, Wilson KS. A longitudinal study of children with day-care experiences of varying quality. Child Dev 1988;59:1286-92.

30 Zahn-Waxler C, Cole P, Richardson D, et al. Social problem solving in disruptive preschool children: reactions to hypothetical situations of conflict and distress. Merrill-Palmer Quarterly 1994;40:98-119.

31 Bijur P, Golding J, Haslum M, et al. Behavioral predictors of njury in school-age children. Am F Dis Child 1988;142: 1307-12.

32 Rivara F, Mueller BA. The epidemiology and causes of childhood injuries. Fournal of Social Issues 1987;43:13-37.

33 Christoffel KSP, Agran PF, Kraus JF, et al. Standard definitions for childhood injury research: excerpts of a conference report. Pediatrics 1992;89:1027-34.

34 Rivara F, Bergman AB, LoGerfo JP, et al. Epidemiology of childhood injuries: sex differences in injury rates. Am $\mathcal{F} D$ is Child 1982;136:502-6.

35 MMWR. Playground-related injuries in preschool-aged children-United States, 1983-1987. $7 A M A$ 1989;260: 2799-800.

36 Mack M, Hudson S, Thompson D. A descriptive analysis of hildren's playground injuries in the United States 1990-4. inj Prev 1997;3:100-3.

37 Mowat D, Pickett W, Brison RJ. A case-control study of risk factors for playground injuries among children in Kingston and area. Inj Prev 1998;4:39-43.

38 American Public Health Association and American Academy of Pediatrics. Caring for our children. National health and safety performance standards: guidelines for out-of-home child care programs. Washington, DC: American Public Health Association, 1992: 410.

39 Whitebrook M, Howes C, Phillips D. The national child care staffing study - who cares? Child care teachers and the quality of care in America. Washington, DC: National Center for the Early Childhood Work Force, 1989.

40 Helburn SW, ed. Cost, quality, and child outcomes in child care centers. Public report. Denver: University of Colorado, 1995.

41 NICHD Early Child Care Research Network. Child care and mother-child interaction in the first 3 years of life. Dev Psychol 1999;35:1399-413.

42 Barnett W. Long-term effects of early childhood programs on cognitive and school outcomes. The Future of Children 1995;5:25-50. 